This article was published in Building and Environment, 92, 182-191, 2015

http://dx.doi.org/10.1016/j.buildenv.2015.04.012

\title{
A sustainability assessment of advanced materials for novel housing solutions
}

Pouya Samani ${ }^{a}$, Adélio Mendes b, Vítor Leal a, João Miranda Guedes ${ }^{a}$, Nuno Correia $\mathrm{c}$, *

a Faculty of Engineering, University of Porto, Rua Dr. Roberto Frias s/n, 4200465 Porto, Portugal

b LEPABE - Department of Chemical Engineering, Faculty of Engineering, University of Porto, Rua Dr. Roberto Frias s/n, 4200-465 Porto, Portugal

c Institute of Mechanical Engineering and Industrial Management (INEGI), Rua Dr. Roberto Frias 400, 4200-465 Porto, Portugal

\begin{abstract}
Material selection is a key step in product design and typically aims at identifying the most suitable material that meets product performance goals at minimum cost. In recent years research has been driven for developing sustainable solutions at competitive costs. This work evaluates the sustainability of advanced sandwich-structured composites for novel housing solutions. Five polymer matrix composite sandwich materials have been selected and compared concerning mechanical, thermal, acoustic and fire performance as well as cost and environmental impact, in order to study both the technical viability and the sustainability of lightweight solutions for prefabricated structural wall panels as well as for new housing; this included mechanical and fire testing of the selected materials. Subsequently, the thermal and acoustic properties of the alternatives were obtained. After performing a cost analysis and environmental assessment, the results of the tests and analyses led to a multi-criteria decision analysis (MCDA); PROMETHEE II (preference ranking organizational method for enrichment evaluation) was used to identify the best alternative. Finally the proposed solution was compared with a typical brick house performance. Higher specific strength, better thermal insulation and lower environmental impacts arose as the main advantages of the proposed structures while acoustic properties and fire safety still need to be improved.
\end{abstract}




\section{Introduction}

The construction industry plays a vital role in the world economy. This sector represents $25 \%$ of the European industrial production and is estimated to account for $14.6 \%$ of global gross domestic product by 2020 [1,2]. Moreover, it is responsible for approximately one third of global carbon emissions [3]. The material selection of any construction is the most difficult and challenging step of any sustainable building project [4]. In the recent years sustainability concept has grown and material selection takes into account not only physical-mechanical properties and technological requirements, but also economic, social and environ- mental issues. Consequently, in order to have a successful innovative product, sustainable requirements must be considered [5].

The energy consumption and $\mathrm{CO} 2$ emissions are the two most considered indicators of sustainability in the construction industry [6]. Some EU countries (e.g. France) have already announced the will to reduce CO2 emissions by $75 \%$ before 2050 [7]. Also, some novel materials contribute to significantly reduce $\mathrm{CO} 2$ emissions: Gonzdez and Navarro [8] concluded that, by careful selection of low environmental impact materials, $\mathrm{CO}_{2}$ emissions can be cut by up to $30 \%$; on the other hand, Goverse et al. [9] suggested that this number can reach ca. 50\%.

Advantages such as prompt construction, better quality, reduced need of resources and less waste have led to an increase in pre-fabricated housing [10]. There is also a growing interest in the use of composite wall systems in prefabrication industry due to lower environmental impact, light weight and lower energy consumption [11]. In addition to the environmental characteristics of these materials, one must also consider other requirements such as mechanical and thermal properties, acoustic performance, durability in specific environments, weight and dimension limits, safety, aesthetic considerations and cost [12]. Therefore, this paper adds environment to the typical design, product and cost selection criteria and proposes a combined material selection method for novel solutions for prefabricated housing [13]. To- wards this end five advanced composite structures were studied concerning mechanical, thermal, acoustic, fire safety, cost and environmental aspects and compared to find the best solution. A multi-criteria decision analysis (MCDA) method PROMETHEE II (preference ranking organizational method for enrichment evaluation) was used to identify the best alternative. At end, the proposed solution was compared with a typical brick house considering technical requirements and midpoint and endpoint environmental impacts.

\section{Literature review}

Numerous studies exist on material selection towards a sustainable construction. However, most have not taken into account all three dimensions of sustainability, i.e. environment, economy and society. Berardi [14] remarkably points out the 
distinction between green and sustainable buildings; green buildings aim at minimizing environmental impact while sustainable building considers economic and social requirements as well.

Life cycle assessment (LCA), structured by international organization for standardization (ISO) 14040 series, is one of the most important tools to quantify environmental impacts of products through their life cycle and has been used in the building sector since 1990. According to ISO 14040 on the LCA framework, there are four following phases for any study: 1) Goal and scope definition; 2) life cycle inventory analysis (LCI); 3) life cycle impact assessment (LCIA); and 4) interpretation $[15,16]$. Moreover, system boundaries define which of three phases of 1) construction, use and end-of-life to include in LCA study of buildings. Accordingly, approaches such as life cycle energy analysis (LCEA) and life cycle cost analysis (LCCA) have been used by numerous researchers to assess sustainability of buildings [17].

Quantifying gas emissions, and in particular $\mathrm{CO} 2$, and embodied energy are two main methods that have been used by several LCA studies to assess environmental impacts of buildings. Some studies such as by Gonzalez and Navarro [8] and by Goverse et al. [9] have estimated the environmental impacts evaluating solely CO2 emissions. Moreover, Dimoudi and Tompa [18] considered SO2 in addition to CO2. Abeysundra et al. [19] have identified three factors of global warming potential, acidification potential and nutrient enrichment potential as main factors impacting the environment and calculated them based on $\mathrm{CO} 2$ and $\mathrm{NO}_{\mathrm{x}}$ emissions. Furthermore, Abeysundra et al. [20] have selected $\mathrm{CO}_{2}, \mathrm{SO}_{2}$ and $\mathrm{PO}_{4}$ to estimate environmental impacts.

Several reports address the embodied energy in building materials. For instance, Reddy and Jagadish [21] studied the common materials used in buildings and compared them based on embodied energy. The studies which assess environmental impacts of buildings in terms of embodied energy can be categorized into two groups of 1) studies that assess contribution of different parts of buildings (e.g. roof, walls, etc.) such as by Dimoudi and Tompa [18], by Reddy and Jagadish [21] and by Thormark [22] and 2) studies that highlight involvement of the different phases of life cycle of building (e.g. manufacturing, recycling, etc.) as studied by Saghafi and Teshnizi [4], by Thormark [22], by Karimpour et al. [23] and by Vefago and Avellaneda [24]. Together, these studies outline that depending on the scope of study, single or multiple midpoints and endpoints can be used to evaluate environmental impacts of buildings. This variety of indicators makes the comparison of different studies very difficult. Therefore, it is suggested that future studies convert the environmental impacts into a common indicator such as equivalent $\mathrm{CO}_{2}$ emissions to allow better comparison.

Berardi [14] claims that the social aspect is the most ignored dimension of sustainability. In recent years, several reports stress the importance of social factors in the selection of materials for the construction industry. Studies, such as by 
Franzoni [12] and by Ljungberg [25], have introduced social factors that must be taken into consideration. Florez and Castro-Lacouture [26] have proposed a mixed optimization model that considers features such as user appeal, functionality and resourcefulness as sustainability dimensions in addition to main technical factors. Normally, social analysis is being performed using questionnaires and personal interviews with individuals, as performed by Abeysundra et al. [19,20], Florez and Castro-Lacouture [26] and Utama and Gheewala [27]. Holopainen et al. [28] point out that from a social perspective, high or low indoor temperatures are main causes of discomfort or distress for the occupants.

Reviewing these studies, one of the major drawbacks of studies on sustainable buildings is that as technological- oriented studies normally lack social inspiration, the social- oriented studies also need to integrate more technical requirements. However, before criticizing lack of social factors, one point that must be noted is the importance of system boundaries and scope of study. There seems to be no compelling reason to argue that LCA studies evaluating manufacturing and end-oflife phases must include as much social factors as those studying use phase.

\section{Experimental material characteristics assessment}

The increasing growth of composites in all industries has influenced the construction industry as well. Over the last decade there has been a significant growth in the use of fiber-reinforced polymers (FRP) in structural engineering [29]. The most common form in which FRP materials are used in constructions is called laminate consisting in a polymer resin reinforced with fiber (e.g. glass, carbon etc.) [30]. In order to obtain the required thickness and increase the bending stiffness, structural concept is used based on a combination of two laminates with a light core between known as sandwich panel or structural insulated panel. This sandwich-structured composite has various advantages such as long-term durability, a high strength to weight ratio, outstanding impact energy absorption and good temperature insulation [30]. In this study, a composite sandwich panel comprising two glass fiber- reinforced laminates sandwiching a polymer core is proposed for novel housing solution.

Glass fibers, as the most common reinforcing fibers for polymer matrix composites, have various benefits such as low cost, high tensile strength, high chemical resistance and excellent insulating properties [30]. The equibiaxial (EBX) woven roving of fiberglass with $\pm 45^{\circ}$ orientation was chosen as reinforcement examining two different combinations of EBX $700 \mathrm{~g} \mathrm{~m}^{-2}$ and EBX $800 \mathrm{~g} \mathrm{~m}^{-2}$. Epoxy and polyester are two main alternative resins for fiberreinforced polymers in structural engineering. However, epoxy resins are preferred due to their adhesive properties, low shrinkage and environmental durability [29]. Also, Pihtili [31] has compared these two resins in fiber-reinforced polyester composite materials and concluded that epoxy has higher wear resistance compared with polyester. Therefore, epoxy was selected as resin for the 
composite sandwich panels. Mechanical tests were performed to assess the stability of matrix and reinforcement.

Thermal resistance, water absorption, mechanical properties, density and cost are main factors in selecting the core of panels [32]. Considering these factors, five polymers foams (i.e. polyurethane (PU 55), expanded polystyrene (EPS 150), expanded polystyrene with graphite particles (EPS+GR 30), extruded poly- styrene (XPS 30) and expanded polypropylene (EPP 60)) were selected. All tested cores were $80 \mathrm{~mm}$ thick and the numbers after abbreviations refer to hardness or compressive strength of the material in different units depending on utilized standard by manufacturer.

\subsection{Mechanical tests}

To assess mechanical properties of the proposed sandwich panel, tensile and compression tests were carried out. The tensile tests were performed for two types of laminates: 1) $700 \mathrm{~g} \mathrm{~m}^{-2}$ glass fiber reinforced plastic (GFRP); and 2) $800 \mathrm{~g} \mathrm{~m}^{-2}$ GFRP. To perform the tests based on standard ISO 527-4, an Instron 4507 universal testing machine was used with a load cell of $300 \mathrm{kN}$ and feed rate of 2 $\mathrm{mm} \min ^{-1}$ at room temperature. To insure statistical relevance, five samples of each alternative (in total 10 samples) with dimension of $250 \times 250 \mathrm{~mm}^{2}$ and thickness of $2 \mathrm{~mm}$ or above were tested. The distance between grips was set to $150 \mathrm{~mm}$.

To examine the compressive strength of five selected polymer cores, tests were performed in accordance with standards ASTM C 364-99 using an Instron 4208 universal testing machine. Maximum loads of $300 \mathrm{kN}$ and the feed rate of 0.50 $\mathrm{mm} \mathrm{min}^{-1}$ were set and experiments run at room temperature. The samples were sup- ported by a steel substrate in order to avoid overall bending. Five samples of each material were tested (in a total of 25 samples) and the average result recorded.

\subsection{Fire performance tests}

Fire performance of the materials in construction industry is of vital importance. The tests were performed according to standard ISO11925-2. A balanced e equibiaxial or EBX e woven roving of fiberglass and five alternative cores of PU, EPS, EPS+GR, XPS and EPP were examined to assess their fire safety performance. Fig. 1 shows the flame chamber machine (Atlas HVUL2 horizontal/vertical) where the tests were performed.

\subsection{Thermal and acoustic properties}

Thermal conductivity coefficient is the primary property in thermal insulation selection [33-37]. However, there are factors such as density, age, operating temperature and material moisture content playing role in value of thermal 
conductivity [34,35,37,38]. Moreover, there are factors such as thermal capacity, thermal reflectivity, emissivity and thermal bridging that affect thermal behavior of building [38-40]. Therefore, in order to understand thermal behavior of building thoroughly, in-door operative temperature and surface temperature need to be inspected through time. Materials with low thermal conductivity have low thermal transmittance ( $U$-value) and high thermal resistance ( $R$-value) and consequently are suitable for thermal insulation [33]. The thermal conductivity of each alternative core at room temperature was provided by the corresponding manufacturer. By having the thermal conductivity and thickness, thermal resistance ( $R$-value) of each core was calculated and compared.

As noise coming from outside a building or from adjacent spaces within a building may be uncomfortable to its occupants, the acoustic characterization of building materials should be taken into consideration [41]. The sound reduction index $R$, which determines the capacity of material to absorb the sound, was used to compare alternatives. Materials with higher sound reduction index have higher capacity to absorb the sound and, consequently, are better sound insulators. Sound reduction index $[\mathrm{dB}]$ was calculated based on mass law for acoustic insulation, Eq. (1) [42]:

$$
R=20 \cdot \log \left(m_{s} \cdot f\right)-47.3
$$

where $f$ is the frequency $[\mathrm{Hz}]$, which was set at $500 \mathrm{~Hz}, m_{\mathcal{S}}$ is the mass per unit area of the panel [kg m${ }^{-2}$ ] for each alternative and 47.3 is a numerical constant.

\subsection{Environmental impacts}

Considering the four steps of LCA that were mentioned before, and that the goal of this study is to assess environmental impacts associated with novel housing materials, the scope is limited to the manufacturing phase and does not include the operational phase and use energy. Furthermore, due to different density of alternative materials in such comparisons, Tabone et al. [43] recommended using the volume instead of mass as functional unit. Therefore, the functional unit of comparison was set to $0.082 \mathrm{~m}^{3}$ of each alternative $\left(1 \mathrm{~m}^{2}\right.$ surface of wall multiplied by $0.082 \mathrm{~m}$ thickness of wall). To perform the LCI and LCIA, Software SimaPro ver. 7 was used. Within this software, IDEMAT 2001 was selected as the database, to collect the required data for LCI, and ReCiPe Endpoint $(H)$ ver. 1.11/Europe ReCiPe H/A was applied as calculation method. The ReCiPe is one of the most recent and harmonized indicator approaches available in LCIA [44,45]. This methodology combines two widely used LCIA methods: 1) CML (midpointoriented) and 2) Eco-indicator 99 (endpoint-oriented) by converting inventory parameters firstly into eighteen midpoint indicators and then three endpoint damage categories. Midpoint indicators facilitate differentiating between various impact categories and endpoint indicators simplify comparing total damage. At 
the end, by assigning weights to three endpoint damage categories of human health, ecosystems and resources, a single score representing total environmental impact is calculated. Values for normalization and weighting vary depending on selected version of the software. There are two references of Europe and World advising different normalization factors. Furthermore, the study timeframe depends on the selection of three perspectives: 1) individualist (I) in favor of short-time interest; 2) egalitarian (E) as the most precautionary perspective; and 3) hierarchist $(\mathrm{H})$ based on the most common policy principles. The used calculation method for this study was ReCiPe Endpoint (H) ver. 1.11/Europe ReCiPe H/A which refers to hierarchist perspective and normalization values of Europe with the average weighting set recommended by the methodology as shown in Table 1 [46].

\subsection{Cost analysis}

Cost, as one of the main dimension of sustainability, must be considered in material selection of the proposed sandwich panel. Cost of the panel including costs of core, resin, fiber and assembling were estimated for each alternative. The estimated cost was not limited to various local suppliers, but also average international cost that was calculated using available data in software application CES EduPack.

\section{Results and discussion}

\subsection{Mechanical tests}

Table 2 presents the results of the tensile tests performed in the EBX proposed laminates. The table shows glass fiber properties as well as those of the selected epoxy resin (CR 83-2). The results show no clear difference between young's

modulus and tensile strength of EBX $700 \mathrm{~g} \mathrm{~m}^{-2}$ and EBX $800 \mathrm{~g} \mathrm{~m}^{-2}$. The compression results are presented in Table 3; EPP showed the best performance with a compressive strength of $1.3 \mathrm{MPa}$ and appropriate compatibility with the laminate. EPS+GR proved to be the best core with the best adhesion to laminate where adhesion is indicated by laminate-core delamination in test. However, the compressive strength is poor compared with the other alternatives.

\subsection{Fire performance tests}

Results of flammability tests are shown in Fig. 2. In it, the flammability of selected materials including laminates and five proposed polymer cores is compared. The samples were classified from A to F, where A (fireproof/non-combustible) is the best and $\mathrm{F}$ is the worst (must not be used for civil applications in Eunøpe). Although cores PU, EPS+GR and XPS are all classified as E, PU showed better fire performance followed by XPS and EPS GR. The other cores, as well as laminate EBX were 
classified as $\mathrm{F}$ implying poor fire safety performance.

\subsection{Thermal and acoustic properties}

Table 4 compares thermal resistance (R-value) and sound reduction index of selected core materials at thickness of $80 \mathrm{~mm}$.

\subsection{Environmental impacts}

Environmental impacts of alternative core materials quantified by total endpoint single score are shown in Fig. 3. EPP shows the highest ReCiPe point of 2.64, followed by PU with 1.85, XPS with 1.65, EPS+GR with 1.33 and EPS with the lowest environmental impact of 0.74 .

\subsection{Cost analysis}

Table 5 compares the estimated cost of selected core materials and Table 6 shows the estimated cost for the resin and fiber materials. Specific glass fiber cost is constant (as per Table 6). Nonetheless, please note that higher mass reinforcements are proportionally more expensive and that any variation in specific glass fiber cost only reflects manufacturing differences.

\subsection{Decision making}

For selected fiber materials, the tensile strength, young's modulus and cost are very similar. The EBX fabric with two layers of reinforcement (one $300 \mathrm{~g} \mathrm{~m}^{-2}$ and one $400 \mathrm{~g} \mathrm{~m} \mathrm{~m}^{-2}$ giving $700 \mathrm{~g} \mathrm{~m}^{-2}$ ) was selected due to tensile strength requirements to be used as reinforcement of the epoxy resin. Table 7 summarizes the properties for selected core materials in combination with laminate of EBX $700 \mathrm{~g} \mathrm{~m}^{-2}$. Moreover, decision making radar chart is presented in Fig. 4 for better comparison of different alternatives.

In recent years numerous multi-criteria decision analysis (MCDA) techniques have been developed to help in selecting the best alternative concerning different criteria. PROMETHEE is an outranking approach based on pair-wise comparison of alternatives and one of the most accepted and widely used MCDA methods [47e50]. While PROMOTHEE I provides partial ranking, PROMO- THEE II offers full ranking of alternatives. Therefore, regarding the purpose of this study, PROMOTHEE II was used for comparison of alternatives. This method firstly sets $N$ number of alternatives $\mathrm{A}=[a 1, a 2, \ldots, a N]$ to be evaluated in terms of $M$ number of criteria $C=[c 1, c 2, \ldots, c M]$. Then it defines $g_{j}(a j)$ as value of alternative $a j$ for criterion $c j$ and consequently Eq. (2) calculates $d j(a 1, a 2)$ as deviation between values of alternatives $a_{1}$ and $a_{2}$ [50]. Considering the deviation, the decision 
maker assigns a preference to the best alternative between 0 and 1 where 0 indicates no preference or indifference and 1 signifies outright preference. This preference indicator is defined as $P j(a 1, a 2)$ and compares each pair of alternatives on that particular as presented in Eq. (3) [48].

$$
\begin{aligned}
& d_{j}\left(a_{1}, a_{2}\right)=g_{j}\left(a_{1}\right)-g_{j}\left(a_{2}\right) \\
& P_{j}\left(a_{1}, a_{2}\right)=F_{j}\left[d_{j}\left(a_{1}, a_{2}\right)\right]
\end{aligned}
$$

There are different preference functions for pairwise comparison of alternatives. The method recommends $\mathrm{V}$-shape preference function for quantitative and usual for qualitative criteria that are respectively calculated by Eqs. (4) and (5) [51,52]. Hence, usual preference function was used for the fire performance as qualitative criterion and V-shape for rest of criteria which are all quantitative. Preference threshold $p$ is the smallest deviation which is considerable as adequate to conclude a full preference.

$$
\begin{aligned}
& \text { Usual preference function } F_{j}\left(d_{j}\right)= \begin{cases}0 & \text { if } d_{j} \leq 0 \\
1 & \text { if } d_{j}>0\end{cases} \\
& \mathrm{V} \text { - shape preference function } F_{j}\left(d_{j}\right)= \begin{cases}0 & \text { if } d_{j} \leq 0 \\
\frac{d_{j}}{p} & \text { if } 0 \leq d_{j} \leq p \\
1 & \text { if } d_{j}>p\end{cases}
\end{aligned}
$$

From this, decision makers define non-negative number of $w j$ as weight of criterion $j$ in accordance to importance of that criterion. Therefore, preference index is denoted as $\mathrm{p}(a, b)$ and is calculated by Eq. (6) [48].

$$
\pi\left(a_{1}, a_{2}\right)=\frac{\sum_{j=1}^{M} P_{j}\left(a_{1}, a_{2}\right) w_{j}}{\sum_{j=1}^{M} w_{j}}
$$

Considering positive outranking flow as defined as $\phi^{+}(a)$, which is calculated by Eq. (7), and negative outranking flow as $\phi(a)$, which is calculated by Eq. (8) [50]. 


$$
\begin{aligned}
& \varphi^{+}(a)=\frac{1}{N-1} \sum_{x \in A} \pi(a, x) \\
& \varphi^{-}(a)=\frac{1}{N-1} \sum_{x \in A} \pi(x, a)
\end{aligned}
$$

Finally, PROMOTHEE II completes the ranking by defining net outranking flow as $\phi(a)$, which is calculated by Eq. (9) [48]. The alternative with the highest value of $\phi(a)$ is the best possible choice [49].

$$
\phi(a)=\phi^{+}(a)-\phi^{-}(a)
$$

Defining weights is a vital step in any MCDA method that must be accomplished by the decision makers [50]. Considering different aspects of this study, the weightings assigned for each factor were 3 for compressive strength, thermal properties, fire performance and acoustic properties, 5 for environmental impact and cost, as dimensions of sustainability, and 1 for laminate-core delamination. The preference threshold $p$ was set to range (difference between maximum and minimum) of values of alternatives for each criterion to obtain a fully linear preference function. The assigned weights and preference factors for all criteria are shown in Table 8.

By inputting values from Tables 7 and 8 and using Software Visual PROMETHEE ver. Academic, the PROMETHEE II analysis was performed which led to the ranking shown in Table 9.

\subsection{Discussion}

Due to high cost, PU did not seem a suitable core material although having high thermal resistance. EPP is a good alternative when mechanical and acoustic properties are required, but it has a high environmental impact. EPS+GR did not fulfill the mechanical requirements in spite of no delamination. EPS proved to be the most environmentally friendly option, though presents high flammability and acoustic properties. Considering all properties, XPS shows the best balance as core material in sandwich panel.

In order to further compare how XPS 30 core composite sandwich panel can be considered a possible housing solution, this structure was compared with a typical masonry building in order to gain insights into benefits and drawbacks. The masonry building was assumed to be composed of a brick wall structure based on standard Eurocode 6 BS EN 1996. The selected brick type was a typical Italian standard hollow brick with dimensions of 500x189x150 $\mathrm{mm}^{3}$. The mortar M5 (Type N, traditional mix II) was selected in accordance to standard BS EN 998 with $10 \mathrm{~mm}$ thickness between the brick layers and $15 \mathrm{~mm}$ thickness on both 
internal and external surfaces of the wall. Fig. A2 and Table A1 provide more details about components of brick wall structure. The mechanical, thermal, acoustic and fire performance of the brick wall were calculated according to Eurocode standards.

A functional unit of $1 \mathrm{~m}^{2}$ of the proposed sandwich panel was compared with the brick wall concerning mechanical, thermal, acoustic, fire safety and environmental aspects. The results of this comparison are set out in Table 10. More details of calculations are presented in Appendix A.

Concerning environmental impact, Software SimaPro ver. 7 was used with IDEMAT 2001 database and ReCiPe Endpoint (H) ver. 1.11/Europe ReCiPe H/A impact assessment calculation method. Table 11 compares the environmental impacts of these two structures at three endpoint damage categories of human health, ecosystems and resources. The results highlight advantage of the proposed sandwich panel in terms of environmental impacts at all endpoint damage categories in comparison with brick wall.

In accordance to ISO 14042 and in order to gain insights into environmental impacts of both scenarios more specifically, characterization of midpoint indicators was calculated by using Soft- ware SimaPro ver. 7 with IDEMAT 2001 database and ReCiPe Midpoint (H) ver. 1.11/Europe ReCiPe H impact assessment calculation method. The midpoint indicators with value zero were omitted and other midpoints were converted to relative scale ranging from 0 to $100 \%$ for better comparison of two scenarios. Fig. 5 compares environmental impacts of the proposed sandwich panel with a typical masonry building at various impact categories. These results point out excellence of the proposed panel in fourteen out of fifteen midpoint categories.

As mentioned in the literature review, there are many former studies that have presented environmental impacts in terms of $\mathrm{CO} 2$ emissions. Thus, by using midpoint indicators and impact category of climate change, the equivalent $\mathrm{CO}_{2}$ emissions for both scenarios were calculated. Software SimaPro ver. 7 with IDEMAT 2001 database was used and to avoid uncertainties associated with different methods, various impact assessment calculation methods were applied. The results of these calculations are set out in Table 12 .

\section{Conclusions}

This article discusses advanced sandwich-structured composites for prefabricated housing. Five alternative sandwich panel structures were studied concerning mechanical, thermal, acoustic, fire safety, cost and environmental properties. Based on PROMO- THEE II multi-criteria decision analysis, sandwich panel consisting of XPS core and glass fiber laminate were selected as the optimal solution. The proposed structure was further compared with brick masonry aiming highlighting the benefits and drawbacks of composites as construction materials.

Results point out that although the proposed sandwich panel has lower compressive strength it has a considerably higher specific strength compared with 
the brick wall. Moreover, having only $7 \%$ of the density of a brick wall is a key advantage of composite sandwich panel in prefabrication industry where low weight materials are needed. The proposed panel has 1.8 times better thermal resistance compared with the brick wall. Furthermore, given the low thermal conductivity of foam core, even better thermal insulation can be obtained by increasing thickness of the wall. Acoustic and fire properties are two areas where brick walls perform better than the proposed panel. Adding surface coatings may be a possible solution to improve these two properties of the proposed panel.

The comparison of environmental impacts shows that the resulting sandwich panel has less environmental impact than the brick wall, highlighting 57\% less total environmental impact. Con- verting environmental impacts into equivalent $\mathrm{CO}_{2}$ emissions, the sandwich panel presented 60\% less $\mathrm{CO}_{2}$ emissions. From the endpoint indicators, it was shown that the proposed panel has $89 \%$ less environmental impact in terms of resources, $55 \%$ less concerning human health and $59 \%$ in the matter of ecosystem quality. Moreover, assessment of midpoint impact categories proved that the suggested structure has significantly lower environmental impacts in urban land occupation, agricultural land occupation, marine ecotoxicity, marine eutrophication, freshwater ecotoxicity, freshwater eutrophication, terrestrial acidification, terrestrial eco- toxicity, particulate matter formation, photochemical oxidant formation, human toxicity, water depletion, fossil depletion and climate change and only shows higher impacts concerning ozone layer depletion. A possible explanation of high impact of the proposed panel on ozone layer depletion might be due to existence of ozone depleting substances such as hydrochlorofluorocarbon (HCFC) in extruded polystyrene. Nevertheless, global trends to phase out HCFC use and current attempts aiming at developing zero ozone depleting foaming agent technologies for extruded polystyrene would decrease environmental impact of the proposed panel.

While former studies on using composite sandwich panel in buildings have mainly focused on thermal properties, density and cost, this research evaluates other factors such as acoustic, mechanical and fire properties of different sandwich panel structures. Moreover, while using a single endpoint indicator of environmental impacts was sufficient for the multi-criteria decision analysis, sustainability of the structure was compared at various midpoint and endpoint impact categories to aid possible future solutions aiming at reducing environmental impact of composite sandwich panels. Furthermore, applying and comparing different impact assessment methods for identifying equivalent $\mathrm{CO}_{2}$ emissions provides higher reliability of results.

\section{Acknowledgment}

The authors would like to thank the Portuguese Foundation for Science and Technology (FCT) for the PhD scholarship SFRH/BD/ 51590/2011 under the framework of MIT-Portugal Program as well as project NORTE-07-024-FEDER- 
000033 e Composite Materials, Structures and Processes, within the Portuguese National Strategic Reference Framework (QREN), through the European Regional Development Fund (ERDF).

\section{Appendix A}

Overall thermal resistance of wall was calculated by summing thermal resistance of components in series or parallel form, as appropriate, considering one-dimensional steady-state heat conduction though plane wall. Thermal conductivity, density and fire performance of components were provided by the manufacturer. By having density, sound reduction index was calculated according to Eq. (1).

Regarding mechanical properties, the compressive strength of the brick wall structure with general purpose mortar was calculated according to the standard Eurocode 6 BS EN 1996, Eq. (A1):

$$
f_{k}=K \cdot f_{\mathrm{b}}^{0.7} \cdot f_{\mathrm{m}}^{0.3}
$$

in which $f_{k}$ is the characteristics compressive strength of the masonry, $f b$ is the normalized mean compressive strength of units and $\mathrm{fm}$ is the compressive strength of the mortar. The values of $f \mathrm{~b}$ and $f \mathrm{~m}$ were measured and declared by manufacturer in accordance to standards EN 772-1 and EN 998-2, respectively. Moreover, $K$ is a constant that is being defined based on type of masonry unit and mortar according to Table 3.3 of the standard Eurocode 6 BS EN 1996. Consequently, set values were $12 \mathrm{MPa}$ for $\mathrm{fb}, 5 \mathrm{MPa}$ for $\mathrm{fm}$ and 0.45 for $K$.

\section{References}

1. Pacheco-Torgal F, Jalali S. Earth construction: lessons from the past for future eco-efficient construction. Constr Build Mater 2012;29:512e9. http:// dx.doi.org/10.1016/j.conbuildmat.2011.10.054.

2. Babatunde OK, Low SP. Chinese construction firms in the Nigerian construction industry. Habitat Int 2013;40:18-24. http://dx.doi.org/10.1016/ j.habitatint.2013.01.002.

3. Giesekam J, Barrett J, Taylor P, Owen A. The greenhouse gass emissions and mitigation options for materials used in UK construction. Energy Build 2014;78:202-14. http://dx.doi.org/10.1016/j.enbuild.2014.04.035

4. Saghafi MD, Teshnizi ZSH. Recycling value of building materials in building assessment systems. Energy Build 2011;43:3181-8. http://dx.doi.org/10.1016/j.enbuild.2011.08.016.

5. Giudice F, La Rosa G, Risitano A. Material selection in the life-cycle design process: a method to integrate mechanical and environmental 
performances in optimal choice. Mater Des 2005;26:9-20. http://dx.doi.org/10.1016/ j.matdes.2004.04.006.

6. GhaffarianHoseini A, Dahlan ND, Berardi U, GhaffarianHoseini A, Makaremi N, GhaffarianHoseini M. Sustainable energy performances of green buildings: a review of current theories, implementations and challenges. Renew Sustain Energy Rev 2013;25:1-17. http://dx.doi.org/10.1016/ j.rser.2013.01.010.

7. Jeanjean A, Olives R, Py X. Selection criteria of thermal mass materials for low-energy building construction applied to conventional and alternative materials. Energy Build 2013;63:36-48. http://dx.doi.org/10.1016/ j.enbuild.2013.03.047.

8. Gonz'alez MJ, Navarro JG. Assessment of the decrease of $\mathrm{CO} 2$ emissions in the construction field through the selection of materials: practical case study of three houses of low environmental impact. Build Environ 2006;41:902-9. http://dx.doi.org/10.1016/j.buildenv.2005.04.006.

9. Goverse T, Hekkert MP, Groenewegen P, Worrell E, Smits REHM. Wood innovation in the residential construction sector; opportunities and constraints. Resour Conserv Recycl 2001;34:53-74. http://dx.doi.org/10.1016/ S0921-3449(01)00093-3.

10. Lawson RM, Ogden RG. 'Hybrid' light steel panel and modular systems. Thin Walled Struct 2008;46:720-30. http://dx.doi.org/10.1016/j.tws.2008.01.042.

11. Manalo A. Structural behaviour of a prefabricated composite wall system made from rigid polyurethane foam and magnesium oxide board.

Constr Build Mater 2013;42:642-53. http://dx.doi.org/10.1016/ j.conbuildmat.2012.12.058.

12. Franzoni E. Materials selection for green buildings: which tools for engineers and architects? Procedia Eng 2011;21:883e90. http://dx.doi.org/10.1016/ j.proeng.2011.11.2090.

13. Zhou C, Yin G, Hu X. Multi-objective optimization of material selection for sustainable products: artificial neural networks and genetic algorithm approach. Mater Des 2009;30:1209-15. http://dx.doi.org/10.1016/ j.matdes.2008.06.006.

14. Berardi U. Clarifying the new interpretations of the concept of sustainable building. Sustain Cities Soc 2013;8:72-8. http://dx.doi.org/10.1016/ j.scs.2013.01.008.

15. Cabeza LF, Rincó n L, Vilariñ o V, Pé rez G, Castell A. Life cycle assessment (LCA) and life cycle energy analysis (LCEA) of buildings and the building sector: a review. Renew Sustain Energy Rev 2014;29:394-416. http://dx.doi.org/ 10.1016/j.rser.2013.08.037.

16. Zuo J, Zhao Z. Green building research-current status and future agenda: a review. Renew Sustain Energy Rev 2014;30:271e81. http://dx.doi.org/ 10.1016/j.rser.2013.10.021. 
17. Asdrubali F, Baldassarri C, Fthenakis V. Life cycle analysis in the construction sector: guiding the optimization of conventional Italian buildings. Energy Build 2013;64:73-89. http://dx.doi.org/10.1016/j.enbuild.2013.04.018.

18. Dimoudi A, Tompa C. Energy and environmental indicators related to construction of office buildings. Resour Conserv Recycl 2008;53:86-95. http:// dx.doi.org/10.1016/j.resconrec.2008.09.008.

19. Abeysundra UGY, Babel S, Gheewala S. A decision making matrix with life cycle perspective of materials for roofs in Sri Lanka. Mater Des 2007;28: 2478-87. http://dx.doi.org/10.1016/j.matdes.2006.09.011.

20. Abeysundra UGY, Babel S, Gheewala S. A matrix in life cycle perspective for selecting sustainable materials for buildings in Sri Lanka. Build Environ 2009;44:997-1004. http://dx.doi.org/10.1016/j.buildenv.2008.07.005.

21. Reddy BVV, Jagadish KS. Embodied energy of common and alternative building materials and technologies. Energy Build 2003;35:129-37. http:// dx.doi.org/10.1016/S0378-7788(01)00141-4.

22. Thormark C. The effect of material choice on the total energy need and recycling potential of a building. Build Environ 2006;41:1019-26. http:// dx.doi.org/10.1016/j.buildenv.2005.04.026.

23. Karimpour M, Belusko M, Xing K, Bruno F. Minimising the life cycle energy of buildings: review and analysis. Build Environ 2014;73:106-14. http:// dx.doi.org/10.1016/j.buildenv.2013.11.019.

24. Vefago LHM, Avellaneda J. Recycling concepts and the index of recyclability for building materials. Resour Conserv Recycl 2013;72:127-35. http:// dx.doi.org/10.1016/j.resconrec.2012.12.015.

25. Ljungberg LY. Materials selection and design for development of sustainable products. Mater Des 2007;28:466-79. http://dx.doi.org/10.1016/ j.matdes.2005.09.006.

26. Florez L, Castro-Lacouture D. Optimization model for sustainable materials selection using objective and subjective factors. Mater Des 2013;46:310-21. http://dx.doi.org/10.1016/j.matdes.2012.10.013.

27. Utama A, Gheewala SH. Influence of material selection on energy demand in residential houses. Mater Des 2009;30:2173-80. http://dx.doi.org/10.1016/ j.matdes.2008.08.046.

28. Holopainen R, Tuomaala P, Hernandez P, Hakkinen T, Piira K, Piipo J. Comfort assessment in the context of sustainable buildings: comparison of simplified and detailed human thermal sensation methods. Build Environ 2014;71: 60-70. http://dx.doi.org/10.1016/j.buildenv.2013.09.009.

29. Bank LC. Composites for construction: structural design with FRP materials. New Jersey: John Willey \& Sons; 2006. http://dx.doi.org/10.1002/ 9780470121429.ch1.

30. Mallick PK. Fiber-reinforced composites: materials, manufacturing, and design. 3rd ed. Boca Raton: CRC Press; 2007. http://dx.doi.org/10.1201/ 
9781420005981.

31. Pihtili H. An experimental investigation of wear of glass fibre-epoxy resin and glass fibre-polyester resin composite materials. Eur Polym J 2009;45:14954. http://dx.doi.org/10.1016/j.eurpolymj.2008.10.006.

32. Mills N. Polymer foams handbook: engineering and biomechanics applications and design guide, chapter 18 e Sandwich panel case study. Oxford: Butterworth Heinemann; 2007. http://dx.doi.org/10.1016/B978075068069- 1/50019-2.

33. Jelle BP. Traditional, state-of-the-art and future thermal building insulation materials and solutions e properties, requirements and possibilities. Energy Build 2011;43:2549-63. http://dx.doi.org/10.1016/j.enbuild.2011.05.015.

34. Pẻ rez-Bella JM, Domínguez-Herná ndez J, Cano-Suñ é n E, del CozDíaz JJ, Álvarez Rabanal FP. A correction factor to approximate the design thermal conductivity of building materials. Application to Spanish façades. Energy Build 2015;88:153-64. http://dx.doi.org/10.1016/j.enbuild.2014.12.005.

35. Domínguez-Muñoz F, Anderson B, Cejudo-Ló pez JM, Carrillo-Andrẻ s A. Uncertainty in the thermal conductivity of insulation materials. Energy Build 2010;42:2159-68. http://dx.doi.org/10.1016/j.enbuild.2010.07.006.

36. Pargana N, Pinheiro MD, Silvestre JD, de Brito J. Comparative environmental life cycle assessment of thermal insulation materials of buildings. Energy Build 2014;82:466-81. http://dx.doi.org/10.1016/j.enbuild.2014.05.057.

37. Kaynakli O. A review of the economical and optimum thermal insulation thickness for building applications. Renew Sustain Energy Rev 2012;16: 415-25. http://dx.doi.org/10.1016/j.rser.2011.08.006.

38. Al-Homoud MS. Performance characteristics and practical applications of common building thermal insulation materials. Build Environ 2005;40: 353-66. http://dx.doi.org/10.1016/j.buildenv.2004.05.013.

39. Civic A, Vucijak B. Multi-criteria optimization of insulation options for warmth of buildings to increase energy efficiency. Procedia Eng 2014;69:911-20. http://dx.doi.org/10.1016/j.proeng.2014.03.070.

40. Kumar A, Suman BM. Experimental evaluation of insulation materials for walls and roofs and their impact on indoor thermal comfort under composite climate. Build Environ 2013;59:635-43. http://dx.doi.org/10.1016/ j.buildenv.2012.09.023.

41. Antó nio J. Fibrous and composite materials for civil engineering applications, chapter 11 e acoustic behaviour of fibrous materials. Cambridge: Woodhead Publishing Limited; 2011. http://dx.doi.org/10.1533/9780857095583.3.306.

42. Long M. Architectural acoustics, chapter 9-Sound transmission loss. 
2nd ed. Waltham: Academic Press; 2014. http://dx.doi.org/10.1016/B978-012-398258-2.00009-X.

43. Tabone MD, Cregg JJ, Beckman EJ, Landis AE. Sustainability metrics: life cycle assessment and green design in polymers. Environ Sci Technol 2010;44: 8264-9. http://dx.doi.org/10.1021/es101640n.

44. Aranda-Usón A, Ferreira G, Ló pez-Sabiró n AM, Mainar-Toledo MD, Bribiả $\mathrm{n}$ IZ. Phase change material applications in buildings: an environmental assessment for some Spanish climate severities. Sci Total Environ 2013;444:16-25. http://dx.doi.org/10.1016/j.scitotenv.2012.11.012.

45. Nucci B, Puccini M, Pelagagge L, Vitolo S, Nicolella C. Improving the environmental performance of vegetable oil processing through LCA. J Clean Prod 2014;64:310-22. http://dx.doi.org/10.1016/j.jclepro.2013.07.049.

46. Goedkoop M, Heijungs R, Huijbregts M, Schryver AD, Struijs J, Zelm RV, et al. 2008: A life cycle impact assessment method which comprises harmonised category indicators at the midpoint and the endpoint level. Report I: char-acterisation. The Netherlands: Ministry of Housing, Spatial Planning and the Environment (VROM); 2009.

47. Kuang H, Kilgour DM, Hipel KW. Grey-based PROMETHEE II with application to evaluation of source water protection strategies. Inf Sci 2015;294:376-89. http://dx.doi.org/10.1016/j.ins.2014.09.035.

48. Troldborg M, Heslop S, Hough RL. Assessing the sustainability of renewable energy technologies using multi-criteria analysis: suitability of approach for national-scale assessments and associated uncertainties. Renew Sustain Energy Rev 2014;39:1173-84. http://dx.doi.org/10.1016/j.rser.2014.07.160.

49. Vinodh S, Girubha RJ. PROMETHEE based sustainable concept selection. Appl Math Model 2012;36:5301-8. http://dx.doi.org/10.1016/j.apm.2011.12.030.

50. Behzadian M, Kazemzadeh RB, Albadvi A, Aghdasi M. PROMETHEE: a comprehensive literature review on methodologies and applications. Eur J Oper Res 2010;200:198-215. http://dx.doi.org/10.1016/j.ejor.2009.01.021. 51. http://www.promethee-gaia.com, [access date: 19.11.14].

52. Brans J, Mareschal B. Multiple criteria decision analysis: state of the art surveys, Promethee methods. New York: Springer; 2005. http://dx.doi.org/ 10.1007/0-387-23081-5_5. 


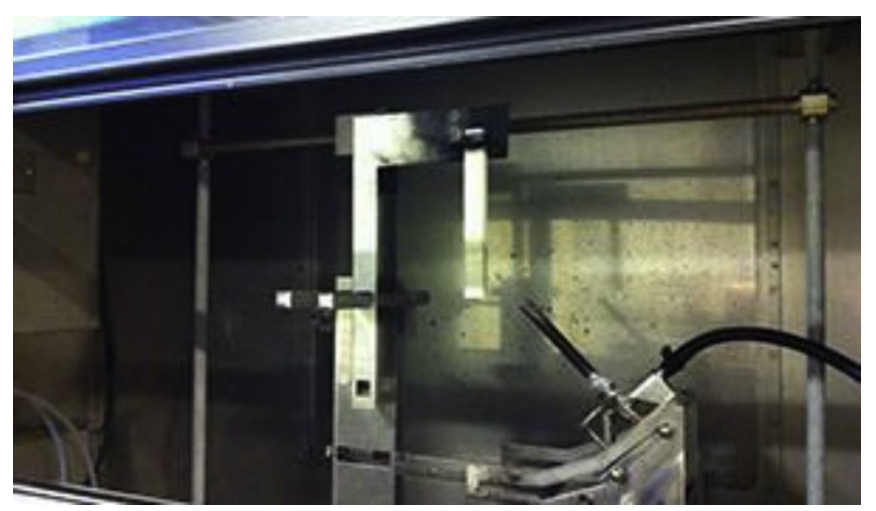

Fig. 1. Flame chamber machine where the fire tests were performed.

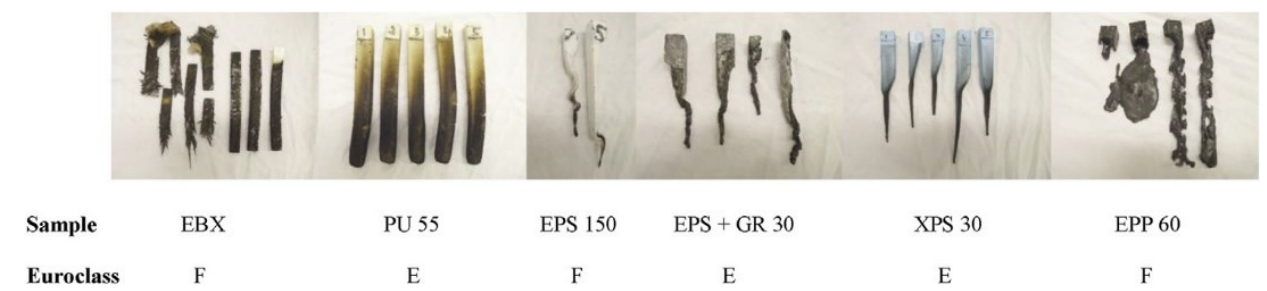

Fig. 2. Results of fire performance tests of selected materials.

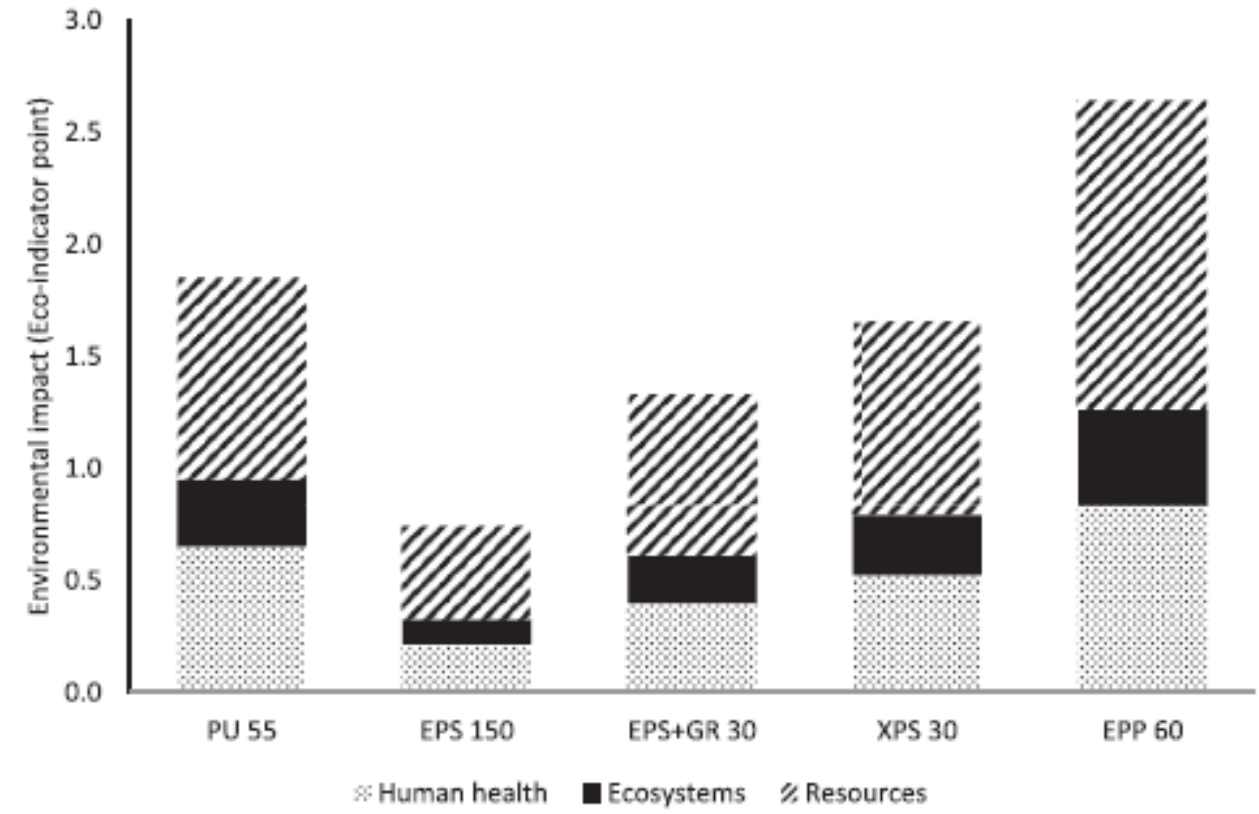

Fig. 3. Endpoint environmental impact of selected core materials. 


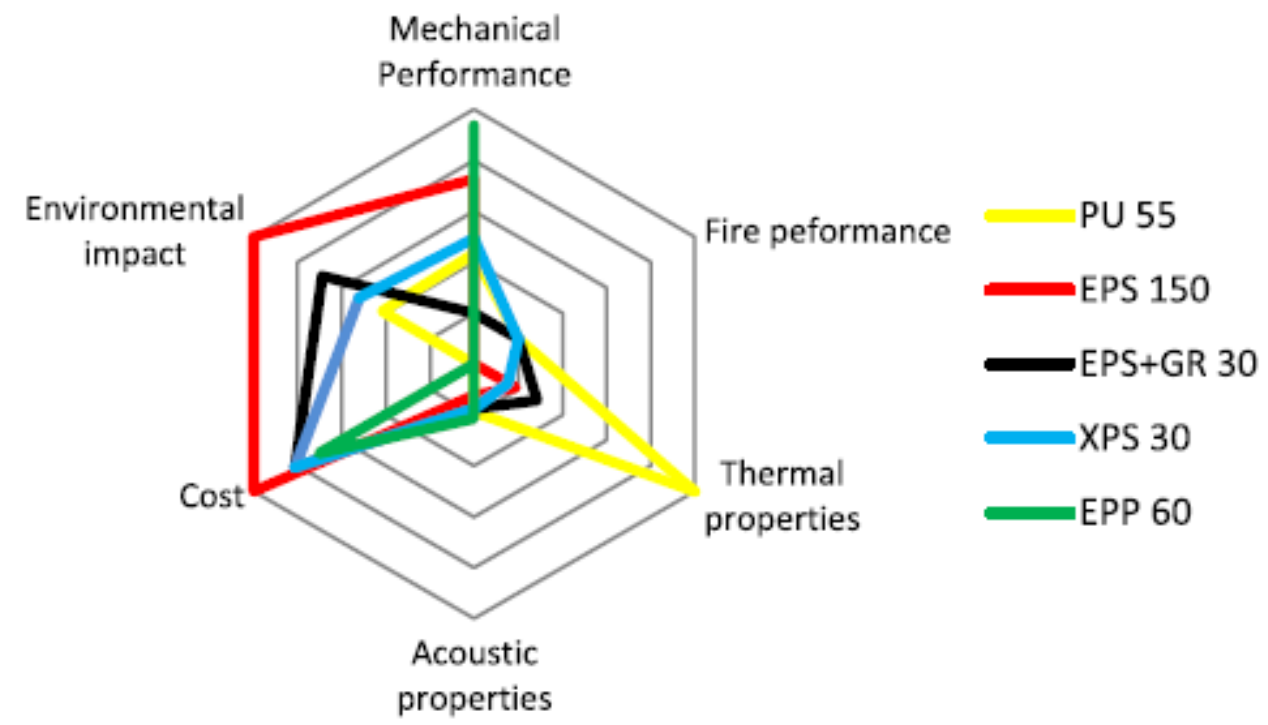

Fig. 4. Decision making radar chart for core material selection

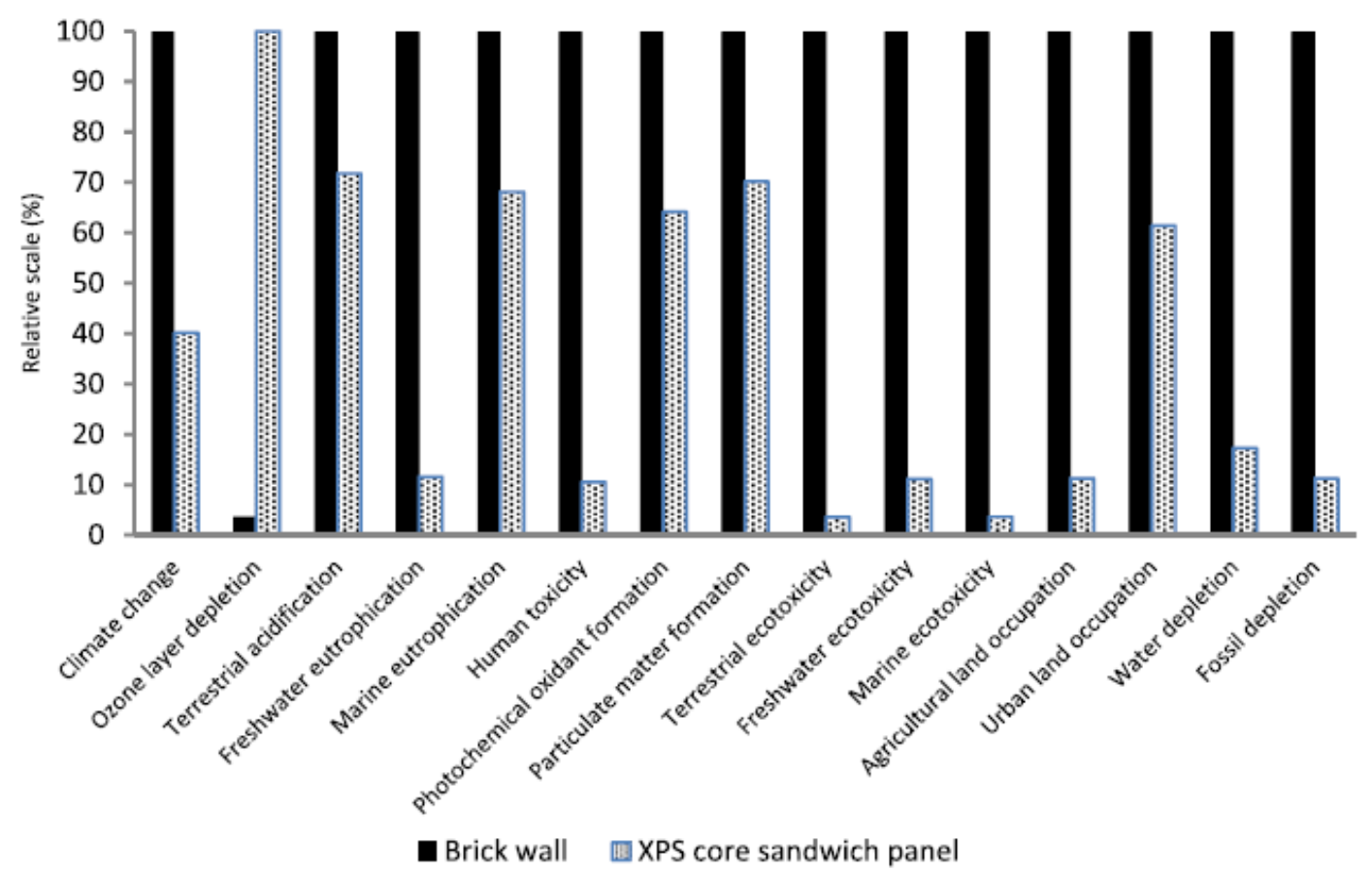

Fig. 5. Midpoint environmental impacts of XPS core sandwich panel and brick wall. 


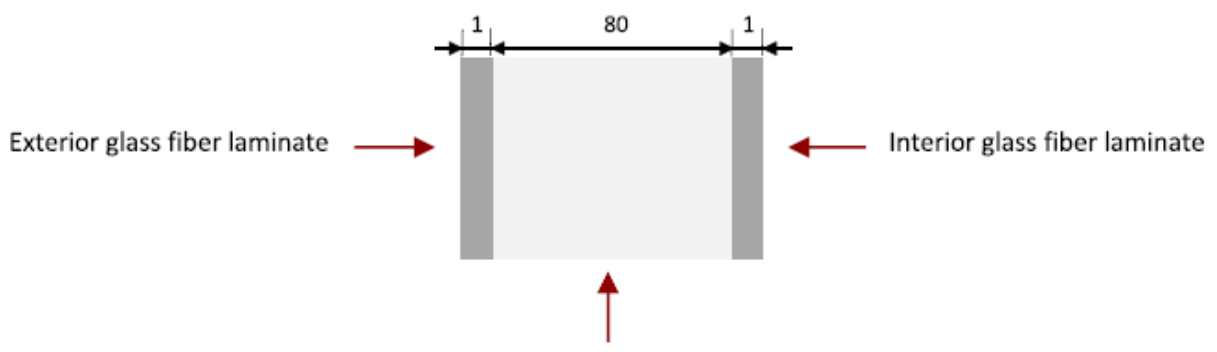

Polymer based foam core

Fig. A1. Proposed panel design comprehending two glass fiber laminates sandwiching a polymer based foam core (all dimensions are in $\mathrm{mm}$

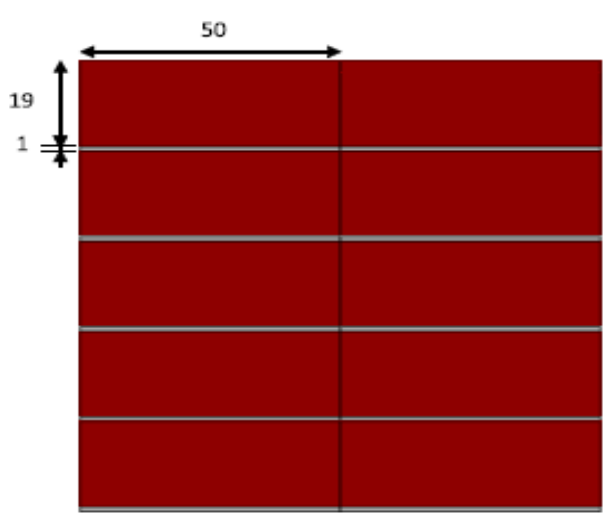

a)

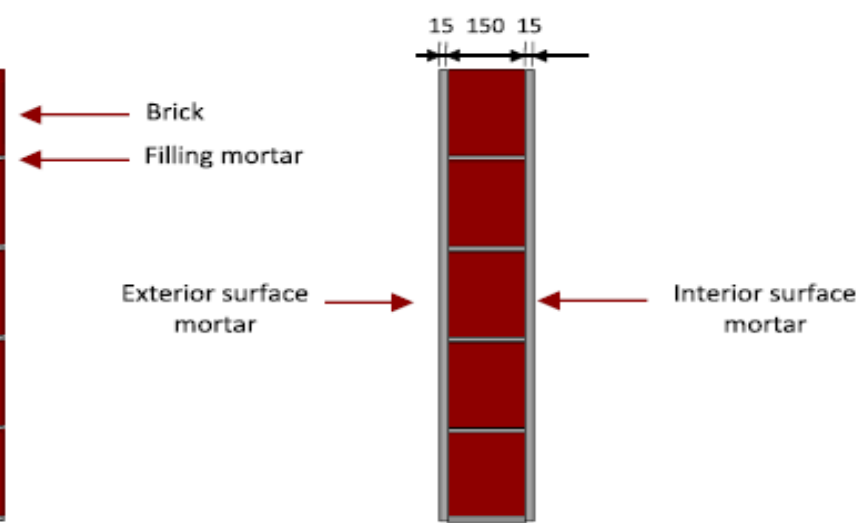

b)

Fig. A2. a) Elevation and b) Section views of brick wall structure (all dimensions are in $\mathrm{mm}$ ). 
Table 1 Normalization and weighting factors recommended by Europe ReCiPe H/A methodology [46].

\begin{tabular}{lcl}
\hline Damage category & Normalization factor & Weight \\
\hline Human health & 49.5 & 400 \\
Ecosystems & 5530 & 400 \\
Resources & 0.00324 & 200 \\
\hline
\end{tabular}

Table 2 Mechanical properties of selected laminates.

\begin{tabular}{lcc}
\hline Sample & Young's modulus [GPa] & Tensile strength [MPa] \\
\hline Raw materials & & \\
Epoxy resin CR83-2 & 2.96 & 84 \\
Glass fiber & 73 & 3400 \\
Laminate (at $0^{\circ}$ orientation) & \\
EBX700 & 8.69 & 100.1 \\
EBX800 & 8.96 & 103.0 \\
\hline
\end{tabular}

Table 3 Mechanical properties of selected sandwich panels.

\begin{tabular}{lllr}
\hline Sample & & Compressive strength-core [kPa] & Compressive strength [kPa] \\
\hline PU 55 & EBX700 & 320 & 1048.75 \\
& EBX800 & 320 & 1305.91 \\
EPS 150 & EBX700 & 150 & 1201.60 \\
& EBX800 & 150 & 967.91 \\
EPS + GR 30 & EBX700 & 60 & 714.90 \\
& EBX800 & 60 & 865.38 \\
XPS 30 & EBX700 & 300 & 1031.38 \\
& EBX800 & 300 & 1213.38 \\
EPP 60 & EBX700 & 400 & 1331.26 \\
& EBX800 & 400 & 1352.81 \\
\hline
\end{tabular}


Table 4 Thermal and acoustic properties of selected core materials.

\begin{tabular}{lll}
\hline Core & $\begin{array}{l}\text { Thermal resistance } \\
{\left[\mathrm{m}^{2} \mathrm{~K} \mathrm{~W}^{-1}\right]}\end{array}$ & $\begin{array}{l}\text { Sound reduction } \\
\text { index [dB] }\end{array}$ \\
\hline PU 55 & 4 & 18.79 \\
EPS 150 & 2.29 & 12.38 \\
EPS + GR30 & 2.50 & 17.47 \\
XPS 30 & 2.22 & 17.47 \\
EPP 60 & 1.90 & 21.44 \\
\hline
\end{tabular}

Table 5 Estimated cost of selected core materials.

\begin{tabular}{lc}
\hline Core & Estimated cost $\left[€ \mathrm{~m}^{-2}\right]$ \\
\hline PU 55 & 21.9 \\
EPS 150 & 4.2 \\
EPS + GR 30 & 7.5 \\
XPS 30 & 7.5 \\
EPP 60 & 9.5 \\
\hline
\end{tabular}

Table 6 Estimated cost of resin and fiber materials.

\begin{tabular}{ll}
\hline Material & Estimated cost $\left[€ \mathrm{~kg}^{-1}\right]$ \\
\hline Resin & \\
Epoxy & 6.90 \\
Polyester & 1.81 \\
Fiber & \\
EBX $300 \mathrm{~g} \mathrm{~m}^{-2}$ & 3.70 \\
EBX $400 \mathrm{~g} \mathrm{~m}^{-2}$ & 3.70 \\
EBX $600 \mathrm{~g} \mathrm{~m}^{-2}$ & 3.70 \\
\hline
\end{tabular}


Table 7 Properties of selected core materials.

\begin{tabular}{|c|c|c|c|c|c|c|c|c|}
\hline Core & $\begin{array}{l}\text { Compressive } \\
\text { strength [kPa] }\end{array}$ & $\begin{array}{l}\text { Delamination } \\
\text { Laminate-Core }\end{array}$ & $\begin{array}{l}\text { Density } \\
{\left[\mathrm{kg} \mathrm{m}^{-3}\right]}\end{array}$ & Fire Euroclass & $\begin{array}{l}\text { Thermal resistance } \\
{\left[\mathrm{m}^{2} \mathrm{~K} \mathrm{~W}^{-1}\right]}\end{array}$ & $\begin{array}{l}\text { Sound reduction } \\
\text { index }[\mathrm{dB}]\end{array}$ & $\begin{array}{l}\text { Environmental impact } \\
\text { [ReCiPe point] }\end{array}$ & Cost $\left[€ \mathrm{~m}^{-2}\right]$ \\
\hline PU 55 & 1048.8 & $95 \%$ & 50.4 & $\mathrm{E}$ & 4 & 18.79 & 1.85 & 41.5 \\
\hline EPS 150 & 1201.6 & $50 \%$ & 24.1 & $\mathrm{~F}$ & 2.29 & 12.38 & 0.74 & 23.9 \\
\hline $\mathrm{EPS}+\mathrm{GR} 30$ & 714.9 & $0 \%$ & 43.3 & $\mathrm{E}$ & 2.50 & 17.47 & 1.33 & 27.2 \\
\hline XPS 30 & 1031.4 & $56 \%$ & 43.3 & E & 2.22 & 17.47 & 1.65 & 27.2 \\
\hline EPP 60 & 1331.3 & $30 \%$ & 68.4 & $\mathrm{~F}$ & 1.90 & 21.44 & 2.64 & 29.1 \\
\hline
\end{tabular}

Table 8 Selected preference factors for PROMETHEE II analysis.

\begin{tabular}{|c|c|c|c|c|c|c|c|}
\hline Preference & $\begin{array}{l}\text { Compressive } \\
\text { strength }\end{array}$ & $\begin{array}{l}\text { Delamination } \\
\text { Laminate-Core }\end{array}$ & Fire Euroclass & $\begin{array}{l}\text { Thermal } \\
\text { resistance }\end{array}$ & $\begin{array}{l}\text { Sound reduction } \\
\text { index }\end{array}$ & $\begin{array}{l}\text { Environmental } \\
\text { impact }\end{array}$ & Cost \\
\hline $\operatorname{Min} / \operatorname{Max}$ & Max & Min & A & $\operatorname{Max}$ & Max & Min & Min \\
\hline Weight & 3 & 1 & 3 & 3 & 3 & 5 & 5 \\
\hline Preference Function & V-shape & V-shape & Usual & V-shape & V-shape & V-shape & V-shape \\
\hline Preference threshold & 616.4 & 95 & $\mathrm{n} / \mathrm{a}$ & 2.1 & 9.06 & 1.90 & 17.6 \\
\hline
\end{tabular}

Table 9 Ranking of selected materials based on PROMETHEE II analysis.

\begin{tabular}{lrl}
\hline Core & $\phi$ & Rank \\
\hline XPS 30 & 0.0659 & 1 \\
EPS + GR 30 & 0.0503 & 2 \\
EPS 150 & 0.0429 & 3 \\
PU 55 & -0.0171 & 4 \\
EPP 60 & -0.1419 & 5 \\
\hline
\end{tabular}


Table 10 Properties of the proposed sandwich panel solution compared with a typical brick wall.

\begin{tabular}{|c|c|c|c|}
\hline Property & XPS core sandwich panel & Brick wall & Unit \\
\hline Compressive Strength & 1031 & 4153 & {$[\mathrm{kPa}]$} \\
\hline Specific strength & 18,418 & 4223 & {$\left[\mathrm{~N} \mathrm{~m} \mathrm{~kg}^{-1}\right]$} \\
\hline Euroclass fire properties & $\mathrm{E}$ & A1 & \\
\hline Density & 66 & 983 & {$\left[\mathrm{~kg} \mathrm{~m}^{-3}\right]$} \\
\hline Thermal resistance & 2.23 & 1.25 & {$\left[\mathrm{~m}^{2} \mathrm{~K} \mathrm{~W}^{-1}\right]$} \\
\hline Sound reduction index & 19.92 & 51.64 & {$[\mathrm{~dB}]$} \\
\hline Environmental impact & 0.65 & 1.50 & [ReCiPe point] \\
\hline
\end{tabular}

Table 11 Endpoint environmental impacts of XPS core sandwich panel and brick wall.

\begin{tabular}{llll}
\hline Damage category & XPS core sandwich panel & Brick wall & Unit \\
\hline Human health & 0.436 & 0.980 & [ReCiPe point] \\
Ecosystems & 0.213 & 0.524 & [ReCiPe point] \\
Resources & 0.0000337 & 0.0002986 & [ReCiPe point] \\
Total & 0.6495338 & 1.5044657 & [ReCiPe point] \\
\hline
\end{tabular}

Table 12 Equivalent CO2 emissions of XPS core sandwich panel and brick wall.

\begin{tabular}{|c|c|c|c|}
\hline Impact assessment calculation method & XPS core sandwich panel & Brick wall & Unit of equivalent $\mathrm{CO}_{2}$ \\
\hline ReCiPe Midpoint (H) ver. 1.11 & 11.6 & 28.9 & {$[\mathrm{~kg}]$} \\
\hline ReCiPe Midpoint (I) ver. 1.11 & 13.4 & 29.1 & {$[\mathrm{~kg}]$} \\
\hline ReCiPe Midpoint (E) ver. 1.11 & 10.9 & 28.8 & {$[\mathrm{~kg}]$} \\
\hline EDIP 2003 ver. 1.01 & 11.6 & 29.1 & {$[\mathrm{~kg}]$} \\
\hline CML. 2001 ver. 2.04 & 11.5 & 29.1 & {$[\mathrm{~kg}]$} \\
\hline IMPACT $2002+$ ver. 2.05 & 10.9 & 29 & {$[\mathrm{~kg}]$} \\
\hline Average & 11.65 & 29 & {$[\mathrm{~kg}]$} \\
\hline
\end{tabular}


Table A1 Thermal properties of components of brick and composite walls.

\begin{tabular}{|c|c|c|c|c|c|}
\hline Construction & Layer & Thickness [m] & Density $\left[\mathrm{kg} \mathrm{m}^{-3}\right]$ & Thermal conductivity $\left[\mathrm{W} \mathrm{m} \mathrm{m}^{-1} \mathrm{~K}^{-1}\right]$ & $\mathrm{R}$-value $\left[\mathrm{m}^{2} \mathrm{~K} \mathrm{~W}^{-1}\right]$ \\
\hline \multirow[t]{5}{*}{ Brick wall } & & 0.18 & 983 & 0.14 & 1.25 \\
\hline & Exterior surface mortar & 0.015 & 1800 & 0.9 & 0.02 \\
\hline & Brick & 0.15 & 800 & 0.82 & 0.19 \\
\hline & Filling mortar & 0.15 & 1800 & 0.9 & 3.33 \\
\hline & Interior surface mortar & 0.015 & 1500 & 0.9 & 0.02 \\
\hline \multirow[t]{4}{*}{ Composite wall } & & 0.082 & 66 & 0.037 & 2.23 \\
\hline & Exterior glass fiber laminate & 0.001 & 1850 & 0.42 & 0.002 \\
\hline & XPS 30 foam core & 0.080 & 43.3 & 0.036 & 2.22 \\
\hline & Interior glass fiber laminate & 0.001 & 1850 & 0.42 & 0.002 \\
\hline
\end{tabular}

